\section{Desenvolvimento Institucional: Estratégia para Elevação da Competência do Órgão Oficial de Turismo}

\section{Vera Lucia Novaes Provinciali}

RESUMO: Trata de uma reflexão acerca das características essenciais do órgão oficial de turismo, sugerindo um roteiro básico para implementação de um Modelo de Desenvolvimento Institucional, com vistas à organização estrutural e funcional face o diagnóstico avaliativo das funções administrativas peculiares às organizações públicas, que têm por finalidade a coordenação e o gerenciamento das atividades turísticas.

PALAVRAS-CHAVE: Desenvolvimento Institucional; turismo; órgão oficial de turismo; estratégia de intervenção; reestruturação organizacional.

ABSTRACT:Thisworkproposesareflectionaboutessential characteristics of public tourism organization and a basic framework for implementation of an Institutional Development Model adequate to both, functional and structural organization. It takes into consideration administrative functions of public organizations, whose objectives are coordination and management of tourism activities.

KEYWORDS: Institutional development; tourism; official tourism entity: strategy of intervention; organizational development; public tourism organization.

\footnotetext{
1. Professora da Universidade Federal de Sergipe - Departamento de Administraçāo. Bacharel em Administraçāo. Mestre em Sociologia Organizacional pela lowa State University - Iowa/USA. Consultora de Turismo do
SEBRAE/SE. Coordenadora do Curso de Pós-Graduação "lato-sensu" em Gerenciamento de Empresas de Turismo.

End.: R. Cristóvāo de Barros, 121, Ed. Saint Tropez, Ap. 804. Praia 13 de Julho. 49020-160 - Aracaju - SE - Brasil Fone/Fax.: (079) 222-3529 - E-mail: vlnp@transnet.com.br
}

\section{Introduçāo}

A procura por uma estratégia normativa, mais ampla de reeducação, levou a adoção do conceito desenvolvimento institucional como forma de intervir nos sistemas de crenças, valores e atitudes, e na própria estrutura organizacional, de maneira que seja possível promover a necessária adaptação e o melhor ajuste ao ritmo acelerado de mudanças que ocorrem no ambiente e na sociedade em geral.

A inserção e interação em sociedades diversas, como no sistema de gestão adotado demanda uma reflexão acerca das características essenciais de um órgão oficial de Turismo, como condicionantes da mudança organizacional operadas em diversas formas, considerando o papel dos agentes internos e o perfil das atividades. Desenvolve-se, a partir daí, a necessidade de se apresentar recomendações que devem ser processadas para a desejada mudança das disposições organizacionais existentes e sua adaptabilidade quanto às modificações tecnológicas, ou seja, os meios pelos quais as tarefas e os serviços devem ser executados.

Este trabalho tem por objetivo, apresentar um relato de experiência tendo por cenário o Estado de Sergipe. Trata-se do esforço para definir um roteiro básico para implementação de um Modelo de Desenvolvimento Institucional, com vistas à organização estrutural e funcional do órgão oficial de Turismo partindo do diagnóstico avaliativo das funções administrativas peculiares às organizações públicas, que têm por finalidade a coordenação e o gerenciamento das atividades turísticas.

A Embratur (1997), no entender da autora, vem trabalhando esta questão tem se utilizado das técnicas de desenvolvimento institucional no nível macro, e com muito sucesso através do Programa Nacional de Municipalização do Turismo PNMT, lançado em 1994. Trata-se de um ambicioso projeto que já apresenta resultados significativos. Cerca de 800 municípios demonstram pleno engajamento nos trabalhos que estão sendo desenvolvidos por este órgão no sentido de otimizar a organização do setor e apoiar os municípios, dotando-os das necessárias condições humanas, técnicas e operacionais, e principalmente dos aspectos relativos à melhoria da mão-de-obra alocada nos órgãos oficiais de Turismo, tanto no nível estadual como municipal (Embratur²,1997).

Desenvolvimento institucional é, neste contexto, traduzido na forma de municipalização, entendida como um processo de engajamento dos municípios potencialmente turísticos, com vistas à conscientização e participação da comunidade nas ações que devem ser desenvolvidas na sua localidade em busca do desenvolvimento auto-sustentável, no qual a profissionalização do órgão oficial passa a ter um papel vital.

Não obstante tais esforços, são necessários maiores esclarecimentos e discussões no que tange às questões relativas ao fortalecimento institucional do setor, em particular os aspectos que devem ser prioritariamente trabalhados e como fazer para se chegar à almejada e correta organização do órgão oficial de Turismo, a

2. Embratur - Instituto Brasileiro de Turismo do Ministério da Indústria, do Comércio e do Turismo 
fim de que o mesmo esteja apto a promover a organicidade do conjunto de relações que permeiam o segmento e desencadear um estilo próprio de gestão através da parceria e comprometimento de entidades, agentes, empresas públicas e privadas.

Assim, reconhecer a necessidade de renovação não é o mesmo que ter a "capacidade" para iniciar tal processo - fato este reconhecido pela coordenação do PNMT. O desafio está na habilidade de reagir-se apropriadamente às situações face uma dinâmica maior de inter-relações e um aumento de interdependência entre governo, empresários, comunidade e no processo educacional como um "todo". Estas forças múltiplas devem ser reunidas num processo de renovação, adaptação e planejamento, a menos que se deseje ver um confronto final entre instituições que se recusam a mudar e críticas não-construtivas. O modelo em tese tem por finalidade visualizar e analisar o conjunto de inter-relações existentes, para, então, executar a necessária mudança e o fortalecimento do órgão gestor de Turismo através do seu respectivo Desenvolvimento Institucional $(D I)^{3}$. Não se trata de um conjunto de regras a ser seguido; pelo contrário, representa uma tentativa no sentido de mover da teoria à prática, tendo como justificativa a necessidade de:

- delinear algumas características das quais partilham os órgãos oficiais de Turismo

- descrever alguns métodos úteis ao estudo científico deste tipo de organização, inclusive o exame de algumas das variáveis cruciais à análise;

- discutir e descrever a mudança organizacional em diversas de suas numerosas formas, considerando o papel dos agentes organizacionais, as recomendações para a mudança das disposições organizacionais existentes e sua adaptabilidade quanto às modificações tecnológicas (meios e formas para execução das tarefas e atividades).

\section{Força do Órgão Oficial de Turismo}

Historicamente consagrada como competência doEstado a garantia do direito à regulamentação para fins da utilização dos atrativos naturais, culturais e históricos, é na alçada da iniciativa privada que "o elemento objetivo do fenômeno turístico traduz-se pelo equipamento receptivo e fornecimento dos serviços para a satisfação das necessidades do turista" (Beni, 1990). Assim, não há como isolar as funções de interdependência entre os agentes responsáveis pelo planejamento, fiscalização e controle da operação (poder público), dos agentes encarregados do gerenciamento, produção, preparação e distribuição dos bens e serviços turísticos (empresários do

3. Esta proposta de $D l$ - Desenvolvimento Institucional, foi apresentada pela autora, enquanto Consultora do Serviço de Apoio às Micro e Pequenas Empresas de Sergipe - Sebrae/SE; para reestruturação orgânica e funcional do orgåo Estadual de Turismo - a Empresa Sergipana de Turismo S/A - Emsetur, vinculada à Secretaria de Estado Federa dergipe-UFSTDpartamento de Administaça. setor). A regulamentação é o principal mecanismo do Estado para fazer com que os "bens subjetivos ou imateriais, não apropriáveis, (...)", como as belezas naturais, sejam verdadeiramente públicos e, ao mesmo tempo, de elevado alcance social, o que de certa forma resulta em objetivos conflitantes, resultantes das necessidades de:

- prover oportunidade e acesso aos locais e atrativos para um maior e diverso grupo de pessoas das diversas classes sociais e interesses, por um lado;

- proteger e evitar a descaracterização dos locais privilegiados pela natureza e cultura original da população dos locais receptores, por outro (Beni, 1990).

Estas necessidades dicotômicas, conflituosas de muitas formas, sinalizam para a análise da relação entre poder e sujeição.

De um lado, observa-se o poder institucional do órgão gestor sobre as atividades turísticas, principalmente resultante da sua potencial força respaldada nas regulamentações e domínio do espaço geo-histórico e cultural, definido como o "potencial de uma unidade social de determinar o comportamento de outra" . O controle, instrumento essencial ao poder, "ajuda a circunscrever comportamentos idiossincráticos e a mantê-los em conformidade com o plano racional da organização" onde a "coordenação e a ordem criadas nos interesses diversos e nos comportamentos potencialmente difusos dos membros é amplamente uma função do controle" (Vieira, 1997). É de se esperar, portanto, que as percepções e relações dos agentes que operam em ambientes institucionais diferentes, como no caso setor público versus setor privado, nem sempre sejam harmoniosas.

Mas, por outro lado, verifica-se a iniciativa privada sendo exposta freqüentemente à sujeição de regras e normas, motivada por razões econômicas, utilitárias e até coercitivas face às penalidades e sanções presentes, levando-a um estágio de alienação pela ausência de apoio e suporte às ações produtivas, resultando no conseqüente enfraquecimento econômico da atividade e até na "morte" prematura de empreendimentos promissores. Sujeição, dentro deste contexto, é entendida como o grau de conformidade dos participantes, decorrente dos diversos mecanismos existentes ao dispor da organização - do órgão oficial de Turismo.

Assim, como forma de conciliar o atendimento a tais necessidades dicotômicas (poder e sujeição) apresentada na relação poder público e iniciativa privada, entendese como de responsabilidade do primeiro;

- estabelecer parâmetros de ocupação determinando os limites da capacidade de utilização dos espaços e dos recursos;

- acompanhar e avaliar os diversos aspectos da demanda atual e futura;

- planejar o escopo das facilidades e equipamentos a serem implantadas nos espaços naturais;

- integrar os planos de desenvolvimento turístico aos programas sociais, econômicos e físicos, para citar os principais. 
No entanto, observa-se que o órgão oficial de Turismo, tem se mostrado bastante despreparado tanto no que tange à habilitação e qualificação dos seus recursos humanos, quanto à disponibilidade de equipamentos e recursos tecnológicos para a operacionalidade exigida e concretização de tal missão. Os profissionais que integram o seu quadro funcional são mal remunerados e freqüentemente destituídos da necessária competência técnica, face à inexistência de programas de capacitação para sua reciclagem e treinamento, o que leva sem dúvida ao mal funcionamento de todo o sistema. O orçamento do órgão oficial de Turismo, por outro lado, em muitos casos apresenta uma "falsa" realidade, contrariando a assertiva de Andrade (1995) de que os recursos financeiros são gastos com "polpudas" folhas de pagamento e equipamentos e para fins outros que não os de sua alçada. Realmente, com raras exceções - os órgãos oficiais de Turismo "funcionam de modo deficiente" e "demonstram-se incapazes de auscultar os sinais da realidade" , mas uma análise mais atenta revela que a amplitude e generalidade com que a atividade turística é entendida, as atribuições e interfaces do órgão com uma diversidade de atividades outras, que não as diretamente ligadas ao Turismo, permite alocação de verbas e pessoal com a finalidade de solucionar problemas imediatistas e emergentes, resultando na aparente impressão de vasto orçamento e recursos.

Assim, pode-se então afirmar que, se por um lado o órgão oficial de Turismo possui o "direito" e dever para controlar, fiscalizar, estabelecer parâmetros e limitações, acompanhar e orientar as ações decorrentes da exploração da atividade, por outro estão despojados e carentes de elementos básicos necessários a um bom desempenho. Comparativamente à iniciativa privada, encontra-se em geral defasado e desatualizado. Reverter o processo é trabalhar a estrutura operacional e funcional do órgão, inclusive pelo fato de que ainda não são tão claras as fronteiras que delimitam o Turismo - por se caracterizar como uma atividade que envolve uma cadeia altamente diversificada e complexa.

\section{Desenvolvimentolnstitucional:Uma Nova \\ Abordagem para um "Velho" Conceito}

A busca pela harmonia entre objetivos públicos e objetivos individuais (empresariais) advindos da iniciativa privada, através da correta estruturação das funções administrativas essenciais ao planejamento, coordenação e controle das atividades turísticas e organicidade do conjunto de relações que permeiam o segmento, é uma alternativa para resgatar a confiança e credibilidade do órgão de Turismo. Denomina-se este processo de Desenvolvimento Institucional (DI).

O termo Desenvolvimento Institucional sugere, à primeira vista, o retorno do "velho" conceito - Desenvolvimento Organizacional (DO), tão utilizado pelos estudiosos das organizações, principalmente os ligados às ciências comportamentais o qual envolve uma coleção de técnicas e métodos com o intuito de se "mudar o comportamento de uma organização - no todo ou em partes - ao se mudar a maneira como os funcionários trabalham, a estrutura da organização ou a tecnologia utilizada" (Montana e Charnov, 1998)

Desenvolvimento Institucional, no entanto, refere-se à procura por uma estratégia normativa, mais ampla, de reeducação - com a intenção de afetar os sistemas de crenças, valores e atitudes do órgão oficial de Turismo, e seus componentes, inclusive corpo gerencial, de maneira que se possa prover a necessária adaptação, melhor ajuste ao ritmo acelerado de mudanças, especialmente as tecnológicas, que ocorrem no ambiente, $\mathrm{c}$ na sociedade em geral.

Dentro desta visão, Desenvolvimento Institucional (DI), ao contrário da tradicional técnica de Desenvolvimento Organizacional, inclui também a reestruturação do seu componente administrativo e do setor como um "todo" integrado, freqüentemente iniciada, facilitada e reforçada por mudanças normativas e comportamentais. Sãotrabalhados tanto os aspectos intra como inter-organizacionais, dentro da abordagem sistêmica conforme defendido por Kaspar(1989) e Beni (1990). Trata-se, sem dúvida, de um esforço educacional muito complexo, destinado a mudar atitudes e valores, comportamentos e a estrutura orgânica e funcional de organização, de tal maneira que esta possa adaptar-se melhor às novas conjunturas, mercados, tecnologias, problemas e desafios que estão surgindo em crescente progressão.

Recentes disposições sobre Desenvolvimento Institucional, constantes das orientações do Prodetur/NE(BNB, 1996), reforçatal entendimento:

com o intuito de contribuir para o desenvolvimento socioeconômico do Nordeste através do reforçoà capacidade da Regiāo em manter e expandir sua crescente indústria turistica, incluir dentro dos três componentes básicos, para as áreas consideradas de expansão turística - o desenvolvimento institucional, aliado às obras múltiplas em infraestrutura básica e serviços públicos, e melhoramentos de aeroportos da Região (BNB, 1996).

Assim, tão relevantes como as obras propriamente ditas de infra-estrutura encontra-se o suporte e o aparelhamento da máquina administrativa. Trabalhar o desenvolvimento institucional de um segmento é segundo o Prodetur/NE (1994):

- Promover o aperfeiçoamento gerencial das empresas públicas e privadas de Turismo do Nordeste e apoiar tecnicamente as administraçōes municipais na área turistica:

- Motivar a criação de Câmaras Setoriais de Turismo nos Estados, Conselhos Comunitários e Organismo de Turismo nos municípios considerados prioritários;

- Elaborar e editar um manual de planejamento turístico municipal que possibilite às prefeituras interessadas, criar seus sistemas municipais de Turismo" (Sudene, 1994).

Estas diretrizes emanadas no documento da Sudene (1994) sãomuito similares às orientações dispostas nos objetivos específicos constantes do documento sobre o PNMT-Programa Nacional de Municipalização do Turismo (Embratur, 1994:9). 
O termo Desenvolvimento Institucional, insere no seu escopo a busca por ações sinergéticas, pela participaçãoc o comprometimento. As mudanças acontecem de fato quando existe um melhor conhecimento quanto ao local em que o órgão gestor se encontra no momento, quanto ao seu objetivo e de como chegar lá.

Os diversos agentes que atuam junto ao segmento demandam "revoluções múltiplas" entendidas como a efetivação da mudança num índice consideravelmente mais rápido do que o atualmente apresentado para que o gestor do processo se direcione à maturidade, e venha se-adaptar e/ou responder às novas condições, mantendo-se "afinado" com as forças internas e externas de mudança, reduzindo ou eliminando possíveis dissonâncias.

A implementação de um $D I$, extrapola o simples intento da busca pela adequada estruturação do órgão. Significa, principalmente, uma forma de se obter o fortalecimento do setor via a necessária habilitação institucional, pois somente assim é possível delinear o perfil do órgão como um agente facilitador, propulsor e integrador de ações.

A cooperação eintegração entre os diversos agentes, a fim de se obter o pleno aproveitamento das atrações naturais e da oferta dos serviços e produtos, respaldado pelo incremento na melhoria da qualidade dos mesmos, permite atrair, receber e concretizar investimentos significativos, tanto do setor público quanto da iniciativa privada no pólo receptor, possibilitando deflagrar um processo organizado e estruturado com uma mobilizaçãoinstitucional mais intensa, através do fortalecimento de uma cadeiade transmissão que começa na estrutura organizacional oficial, passa pela sociedade e se completa nainiciativa privada - ou seja, utilizaro Desenvolvimento Institucional enquanto estratégia de elevação de competência.

É uma forma de favorecer e incentivar a articulação entre o poder público e a iniciativa privada, ao contrário de ações isoladas de baixo impacto para a economia. Objetiva-se desencadear e fortalecer projetos turísticos integrados, estabelecer parcerias sólidas, gerar idéias novas e criativas, conjugar esforços no sentido de promovera "somação", inclusive noquetange ao incremento da própria comercialização do produto turístico através da divulgação e promoção institucional das atrações e potencialidades, consorciada à necessária produção dos bens e serviços turísticos de responsabilidade do empresariado.

\section{Modelo ${ }^{4}$ de Desenvolvimento Institucional}

O poderdo órgão oficial para planejar, fiscalizare controlar a atividade turística com racionalidade - impor restrições, exercer controle e solicitar sujeições, são atribuições intrínsecas ao órgão gestor para rcalização de suas funções, demandando

4. Modelo, refere-se a um conjunto integrado de características que permite retratar uma situaçāo, evento, fenômeno, setor ou organizaç̄o a partir de um determinado ponto de vista ou dimensāo. por consegüinte, a necessária reformulação tanto da sua cstrutura funcional, como orgânica - ou seja, trabalhar de forma integrada a estrutura organizacional, o sistema de planejamento, o sistema de informações, o desenvolvimento dos recursos humanos e o sistema de marketing turístico.

Os pressupostos básicos do Modelo de Desenvolvimento Institucional residem no fato de que:

- a atividade turística resulta do somatório de recursos naturais e artificiais (feitos pelo homem - equipamentos e serviços) com um "campo de estudo abrangente, complexo e multicausal", e como tal demanda um quadro referencial dinâmico, flexível, adaptável, de fácil leitura e compreensão para organizar esse imenso complexo de fatores (Beni, 1990);

- o órgão oficial de Turismo faz parte de um tipo de organização formal (poder público), em que suas partes componentes são interdependentes, e no qual o mesmo tem a finalidade de promover o "linkage" com o sistema maior e proporcionar vias para seu controle e integração (Gouldner 1959:405-410);

- a necessidade imperativade investigar os relacionamentos teóricos entre os vários aspectos do ambiente global (indústria turística) e organizacional, com forma de "conhecer" e aplicar o conhecimento adquirido, proporcionando um referencial que permita maior objetividade para sua operacionalização.

Os diversos elementos - poder público, iniciativa privada e comunidade -, devem interagir de forma sistêmica com a finalidade de permitir uma integração harmônica, e proporcionar uma maior racionalidade na aplicação dos recursos necessários e maior efetividade na consecução das ações inerentes ao proccsso de reforçar a capacidade da localidade receptora em manter e expandir sua indústria turística, e contribuir efetivamente para o desenvolvimento sócio-econômico, com a necessária elevação da renda e do emprego, considerando-se os seus efeitos diretos e indiretos através da revitalização e estruturação do órgão oficial de Turismo e do setor.

A transformação da situação atual, em um cenário que considera o setor de forma integrada, espacial, social e economicamente, tanto no que se refere aos aspectos ligados à oferta, como à demanda, pressupõe:

- existência de articulação e de adesão entre os participantes do universo ofertante: poder público, comunidade e empresários;

- funcionamento a contento de um sistema de planejamento, de um sistema de informação e de um sistema de promoção (marketing);

- desenvolvimento de conhecimentos e habilidades específicas daqueles que operam o setor, tanto no nível técnico, quanto nos níveis operacionais e gerenciais

Trata-se de um estilo de gestão participativa inerente à condução de uma política norteadora para o desenvolvimento institucional, destinada à dinamização do segmento turístico. 
As intervenções propostas pelo Modelo de Fortalecimento Institucional, conforme apresentada nestc trabalho, devem permitir uma articulação sistêmica de ações organizadas, confluindopara a elevação dacompetência político-institucional, tendo como eixo central a cvolução do desempenho gerencial do setor, de forma cumulativa, ampliadae crescente, principalmente quando se observa tal multiplicidade de grupos - órgãos, entidades c empresas que integram a "indústria turística"

A mudança comportamental scrá o resultado das mudanças estruturais procedidas, tanto internamente no órgão, como externamente, facc à interação contínua.

A Figura 1 demonstra a estrcita inter-rclação entre as áreas abordadas no modelo com vistas ao desenvolvimento institucional do setor promovendo, concomitantemente, o fortalecimento do órgão oficial de Turismo de um Estado ou Município, visto a interdependência das partes, proporcionando meios para scu controle e integração.

Conforme defendido por Hall (1972b:4), o estudo e a análise das funções desempenhadas pelo órgão gestor permite a determinação das características que sc acham interrelacionadas, mesmo quando a análise do "todo" enquanto um fenômeno social seja entendida como estática em determinado momento do tempo.

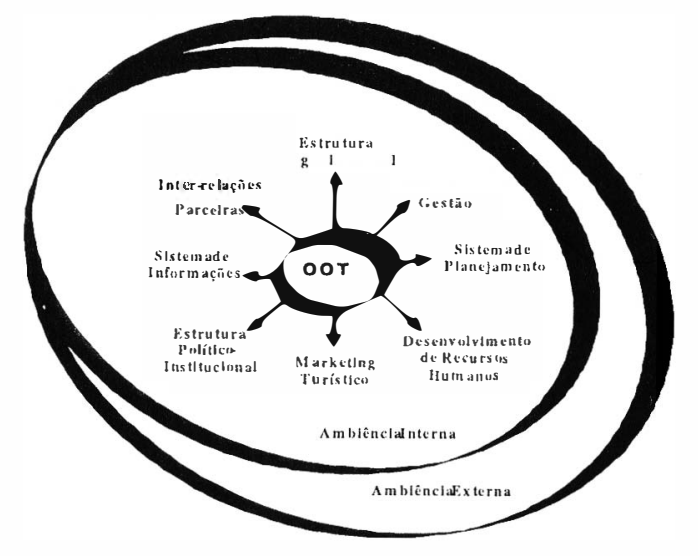

FIGURA 1 - ÁREAS FOCO

Estas funções se apresentam como imperativos funcionais independentes para que não só o órgão gestor, mas o próprio setor turístico, no qual sc insere, possa sobreviver, progredir e alcançar a maturidade no decorrer do tempo. Portanto, o exame dos inter-relacionamentos funcionais, bem como a relação com o "todo" e seu ambiente externo deve reconhecer e abranger as seguintes variáveis:
- Capacidade do órgão gestor para o estabelecimento e consecução de metas definidas

A eficácia do órgão gestor é avaliada em termos da sua habilidade para promover a melhoria sócio-econômica da localidade, com o resultante aumento do nível de renda e emprego e melhor posicionamento do pólo receptor junto aos pólos emissores, destacando o estímulo à maior participação de empresas e empreendimentos no mercado e incremento do fluxo turístico.

- Mobilização dos meios técnicos e operacionais

Para o atingimento das metas é analisado em termos do dimensionamento dos recursos humanos, materiais e tecnológicos, refletindo o grau de adaptação para responder às demandas externas. Trata-se de estudos e pesquisas, material informativo e promocional como forma de subsidiar a atuação dos empresários e atrair investidores, além de incentivar a preservação do ambiente natural, a fisionomia social e cultural com base em dispositivoslegais, via manutenção de um adequado sistema de informações.

- Manutenção de relações sociais e emocionais

Relações apropriadas entre os que cooperam e contribuem para a consecução das metas é outroimperativo funcional do órgãogestor. Obtém-se através da integração dos diversos agentes externos refletida pelo modelo de gestão adotado. Quanto mais participativo for o modelo de gestão, maior será o grau de integração. A existência de conselhos com lideranças participantes, de um fórum colegiado, onde as decisões são tomadas de comum acordo pelas diversas representações pública or an racınna e privada - pelos diversos grupos interagentes, são indicadores deste aspecto.

O estudo destas variáveis permite proceder o exame dos inter-relacionamentos funcionais, bem como a relação entre o "todo" e seu ambiente externo - intra e inter-organizacional,- para atender imperativos funcionais independentes (Parsons, 1951, 1956a; Morse, 1961:113-115).

As unidades existentes nos órgãos oficiais de Turismo, funcionam para assegurar que cada um dos imperativos citados seja trabalhado e resolvido em base continuada. As unidades são estabelecidas de acordo com as suas funções, sejam elas de planejamento e coordenação, gerenciais, de inspeção para o controle de qualidade e de definição e estabelecimento de políticas.

O modelo permite, portanto, o exame não só dos inter-relacionamentos funcionais das diversas unidades integrantes (departamentos), mas também a relação do órgão como um todo e seu ambiente externo (fenômeno turístico). O desenvolvimento institucional atua como um mecanismo regulador dos setores de trabalho, das atividades inerentes às unidades integrantes do órgão, possibilitando, dessa forma, a intervenção e a adequação do mesmo às demandas internas e externas. As metas do órgão oficial de Turismo são, então, compreendidas e estudadas face às partes componentes de cada sub-sistema. 


\section{Examinando os Sub-Componentes do Modelo}

A necessária intervenção e conseqüente atingimento das metas pretendidas é obtida através do estudo dos sub-sistemas ou sub-componentes que integram o Modelo de DI, ou seja:

- Sub-Componente Organizacional (Estrutura Organizacional)

- Sub-Componente Desenvolvimento de Recursos Humanos

- Sub-Componente Planejamento

- Sub-Componente Sistema de Informações

- Sub-Componente Marketing Turístico

A Figura 2, a seguir, apresenta as inter-relações dos diversos sub-componentes integrantes do Modelo de Desenvolvimento Institucional.

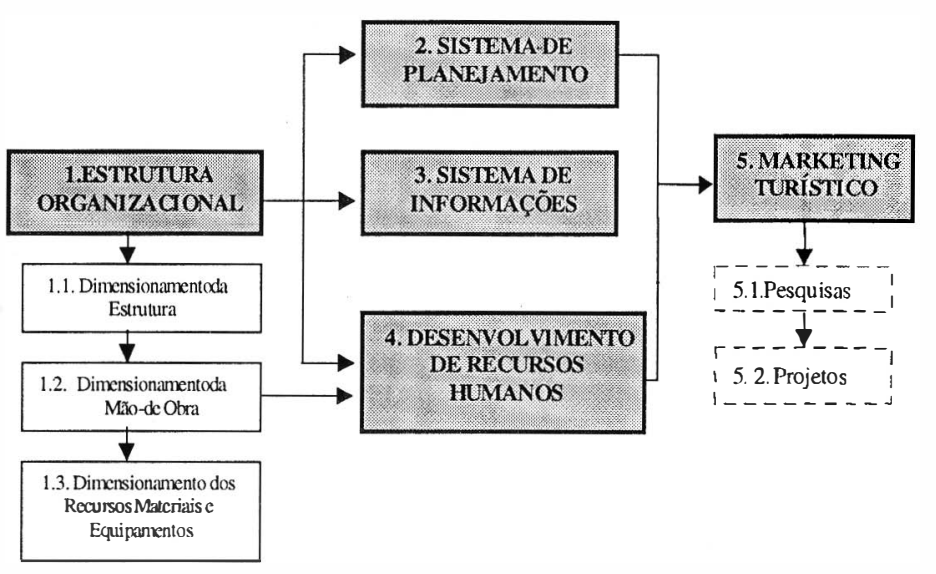

\section{FIGURA 2: INTER-RELACIONAMENTO DOS SUB-COMPONENTES}

Cada um dos sub-componentes ${ }^{5}$ deve ser estudado e especificado em termos dos seguintes aspectos:

- situação atual envolvendo análise e descrição das condições existentes, seus aspectos positivos e negativos.

- objetivos que serão perseguidos;

- metas representadas pelo estabelecimento da melhor maneira para resolver os pro-

5. Conforme orientação do BNB, 1996 blemas detalhando as diversas fases de preparação, diagnóstico, concepção, desenvolvimento, implantação e gerenciamento/ações específicas independentes; - atividades envolvidas para a consecução de cada uma das metas propostas;

- produtos resultantes ou o resultado pretendido face as metas estabelecidas.

- metodologia, especificando como o trabalho será desenvolvido.

As inter-relações dos produtos e atividades de cada um dos componentes ou sub-sistemas são apresentadas nas Figuras 3 e 4.

A sincronicidade apresentada na Figura 2, serve de roteiro às diversas etapas subseqüentes, onde primeiramente se trabalha a área foco - estrutura organizacional - Figura 3, inclusive no que tange aos recursos humanos - suas potencia

limitações; ao tempo em que são operacionalizados aspectos relativos ao Sistema de Informações, a definição dos Sistemas Operacionais a serem implantados e os respectivos equipamentos necessários.

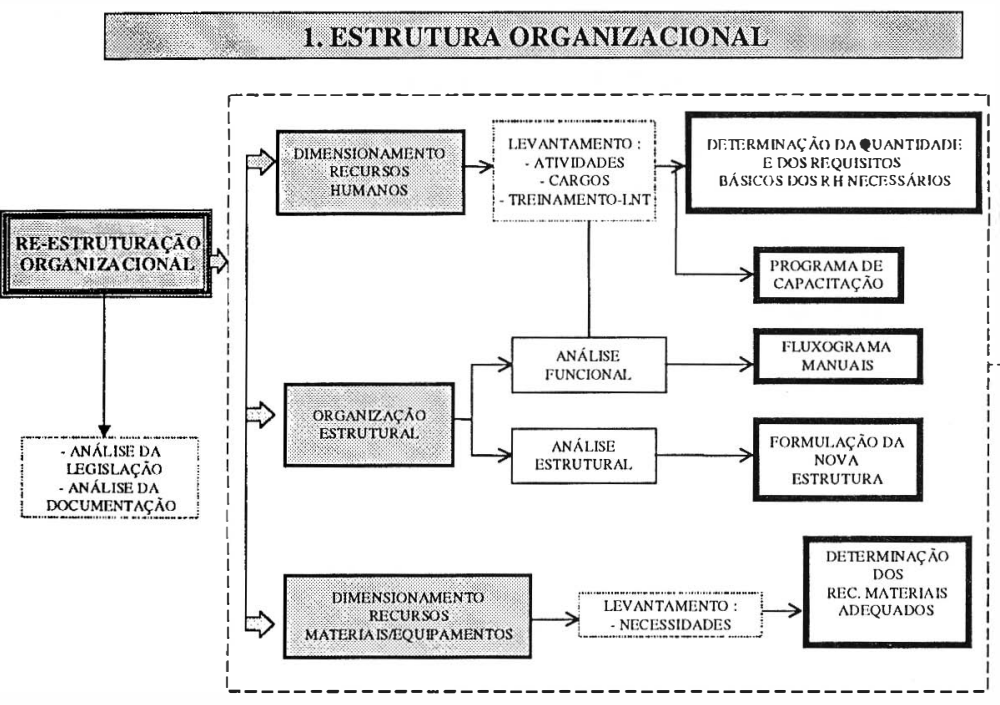

FIGURA 3 - ÁREA FOCO: ESTRUTURA ORGANIZACIONAL

O Sistema de Planejamento - (Figura 4), apresenta duas vertentes: uma interna às atividades operacionais do órgão, outra voltada para o planejamento do setor como um todo, inclusive a filosofia de implantação de um modelo de gestão participativa, agregando outras instituições, órgãos e entidades e/ou o "trade" turístico. 


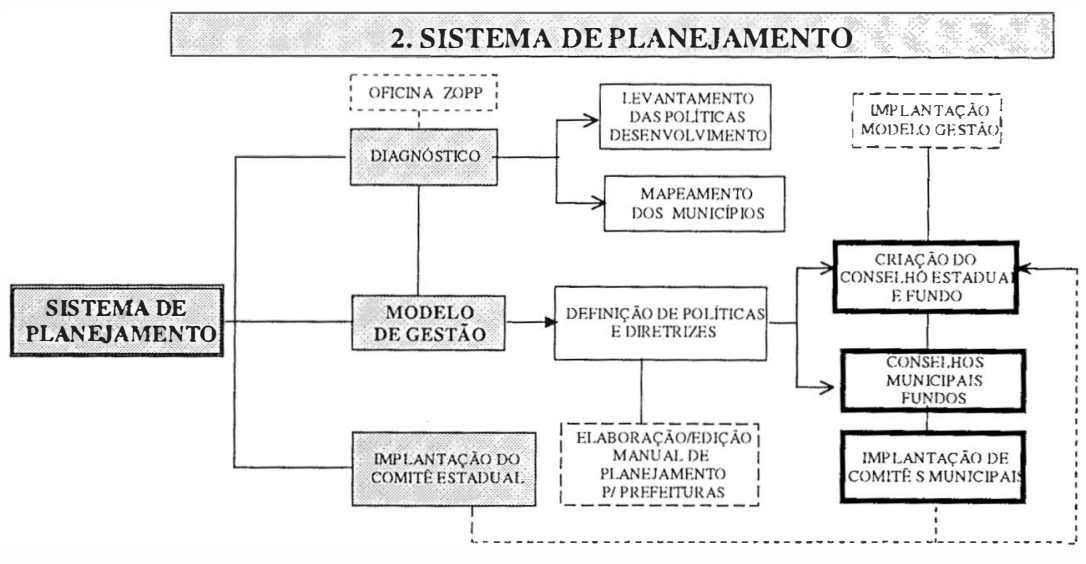

FIGURA 4 - ÁREA FOCO: SISTEMA DE PLANEJAMENTO

O Sistema de Informaçōes Turísticas tem por objetivo registrar e prestar informações sobre os equipamentos, serviços, atrativos turísticos, dentre outras informações relevantes sobre o setor. Para seu desenvolvimento utilizando-se de "softwares" específicos, recomenda-se o assessoramento técnico de profissionais da área de Informática, responsáveis pela implantação da rede de informações, o desenvolvimento dos sistemas informatizados e principalmente, o treinamento do pessoal do órgão, viabilizando os produtos relacionados na Figura 5 - Área Foco Sistema de Informações.

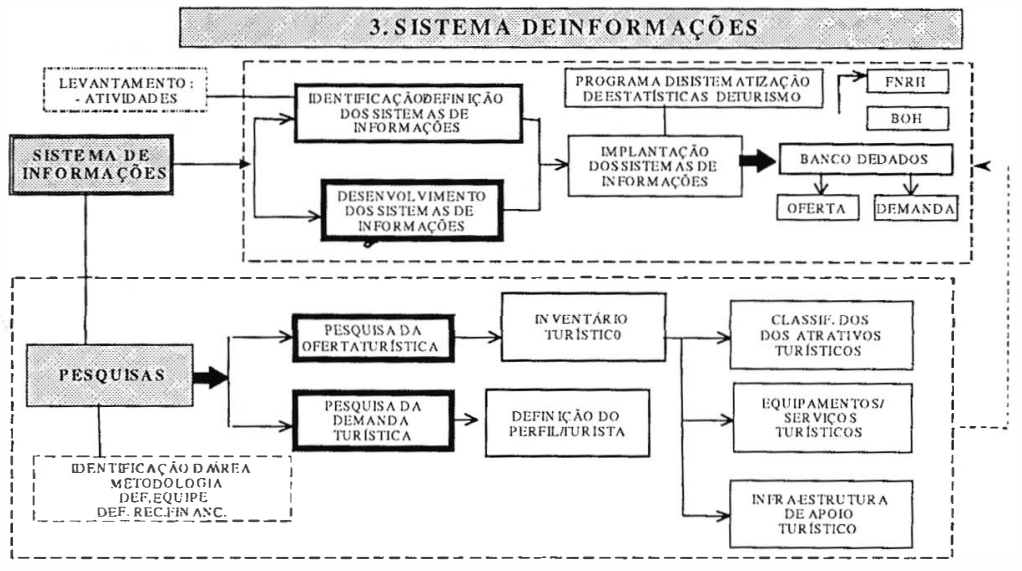

FIGURA 5 - ÁREA FOCO: SISTEMA DE INFORMAÇŌES
Os aspectos relativos ao desenvolvimento dos recursos humanos (Figura 6) também são analisados sobre duas óticas distintas, mas convergentes: a capacitação dos profissionais que trabalham (alocados) no órgão (cliente interno) e a capacitação daqueles que atuam no setor (cliente externo). Quanto ao primeiro, é procedido o treinamento em serviço à medida que as atividades vão sendo implementadas e/ou modificadas, e assim adotar um sistema de "aprender-fazendo" sob a devida orientação e o treinamento formal propriamente dito, através de cursos, seminários de sensibilização e conscientização, conforme o resultado do levantamento de necessidade de treinamento. A capacitação dos recursos humanos envolve não só o desenvolvimento de habilidades técnico/operacional, mas também o desenvolvimento da habilidades conceituais e humanas, e capacitação gerencial. A conscientização e capacitação da comunidade e empresáriosé promovida em parceria com entidades envolvidas no processo de formação de profissionais, tais como, universidade, Sebrae, Senac e organizações não governamentais, por exemplo.

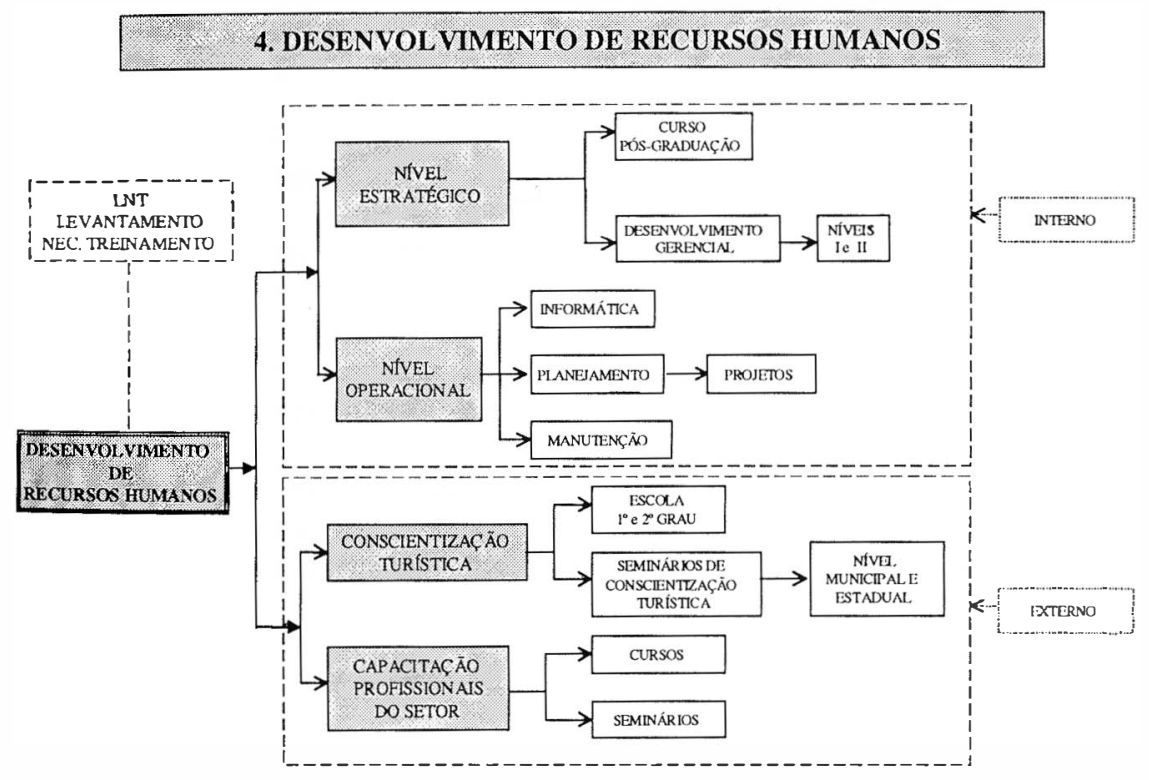

FIGURA 6 - AREA FOCO: DESENVOLVIMENTO DE RECURSOS HUMANOS

As atividades relativas à área foco: Marketing Turístico - (Figura 7), visam atrair e responder satisfatoriamente à demanda e incrementar o fluxo turístico, via desenvolvimento de pesquisas e material informativo sobre o núcleo receptor com a finalidade de coletar e registrar as informações necessárias à solidificação do 
mesmo, como um pólo receptivo com capacidade competitiva respeitável, tanto a nível nacional como internacional.

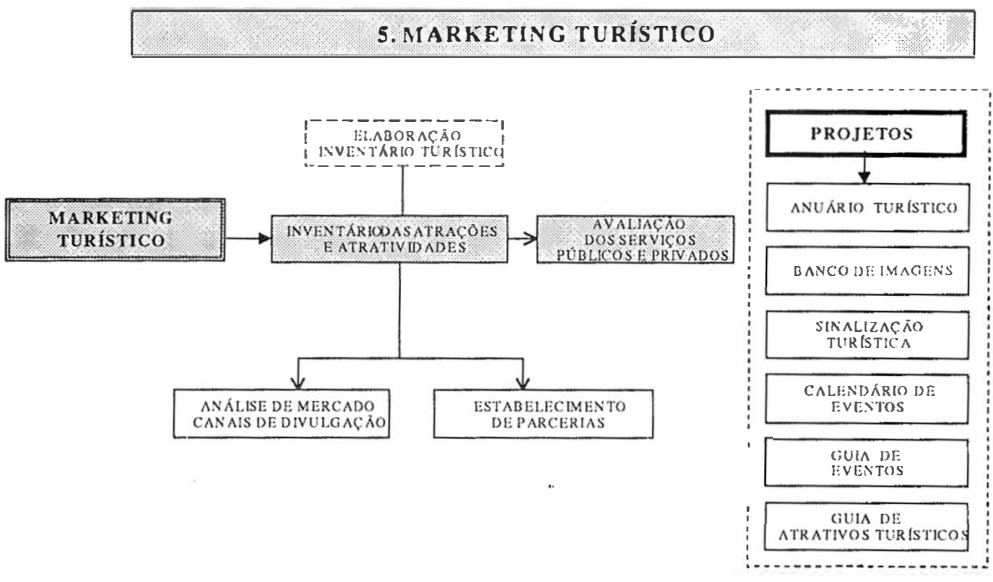

FIGURA 7 - ÁREA FOCO: MARKETING TURISTICO

Pelo exposto, os imperativos funcionais descritos abrangem os três níveis de unidades:

- o nível da consecução de metas em direção aos objetivos pretendidos;

- o nível da adaptação via mobilização dos meios técnicose operacionais necessários ao atingimento das mesmas;

- o nível da integração inter e intra-organizacional como forma de obtenção da necessária cooperação para constituir ou reconhecer os tipos de capacidade que o sistema necessita, e assim dinamizar o setor de forma integrada.

\section{Consideraçōes Finais}

Contribuir para fortalecer uma perspectiva multidimensional ao se estudar o órgão oficial de Turismo é um esforço revelado pelo Modelo de Desenvolvimento Institucional. Este permite a melhor estruturação e organização do sistema responsável pelo desenvolvimento de uma atividade altamente caracterizada por interdependências intrínsecas, onde uma diversidade incrível de agentes mantém constante interação. O elevado grau de interconexão dos problemas demandam a reorganização institucional dos setores ligados ao Turismo e, ainda, progressivamente, maior envolvimento entre os profissionais e gestores, com a sociedade empresarial. O órgão oficial de Turismo é o grande agente propulsor da atividade numa localidade e como tal deve apresentar uma postura proativa e mobilizadora de esforços.

A limitada existência de informações que orientam a implementação de ações de Desenvolvimento Institucional, na literatura é inquestionável. Raramente observam-se trabalhos como o apresentado pelo Banco do Nordeste do Brasil S. A. - BNB (1996), o qual tem por objetivo disciplinar e orientar as intervenções governamentais propostas (planos, estudos, treinamentos e outros produtos) que ensejam suporte financeiro, e portanto, são pouco acessíveis à comunidade acadêmica.

Quando se trata da operacionalização do Modelo de Fortalecimento Institucional para órgãos gestores de Turismo, entende-se que há necessidade de uma estrutura de projeto de Desenvolvimento Institucional, de um roteiro flexível, condizente com as diversas realidades e estruturas funcionais, no qual se apresente a essência das atividades inerentes ao DI destacando que:

- as mudanças somente podem ser efetivadas a partir de uma reestruturação e organização adequada precedidạ de estudos técnicos;

- toda mudança incorporada deve estar alicerçada na análise do desempenho do órgão em relação ao seu contexto global, para que a sua competência seja fortalecida;

- o apoio do órgão gestor é determinante para o sucesso de qualquer programa, e as ações devem ser consistentes e mantidas ao longo do tempo;

- cada parte do processo deve estar consciente e comprometida com o seu papel na consecução da melhoria ensejada. Esse comprometimento é conseguido por meio do desenvolvimento de habilidades e competências técnica, humana e conceitual.

O poder do órgão gestor de Turismo, embora respaldado por prescrições legais, depende de sua capacidade técnica e política de efetivamente exercer seu poder regulador, fiscalizador e mobilizador, sendo indispensável que se atue no sentido de garantir a característica social do Turismo. O futuro aponta para uma tendência de maior competição exigindo mais qualidade na prestação de serviços por parte de todos que atuam junto ao setor, sendo primordial levar em conta que o fortalecimento e elevação da competência do órgão oficial de Turismo deve partir de diagnósticos e estudos intra e inter-organizacional, que permitam o desenvolvimento das principais áreas-chave, conforme apresentada no presente modelo, ou seja:

- estrutura organizacional;

- sistema de planejamento

- marketing turístico;

- desenvolvimento de recursos humanos;

- sistema de informações.

O desenvolvimento institucional, por consegüinte, só pode ser entendido 
dentro da dimensão relacional e política. O presente trabalho sugere a existência de interdependência entre o poder do órgão e sua competência funcional para o exercício das suas atribuições, e análises similares devem ser estendidas no sentido de se verificar se novos indicadores emergem, ampliando os focos e bases aqui apresentados.

\section{Referências Bibliográficas}

ANDRADE, José Vicente de. 1995. Turismo: fundamentos e dimensões. São Paulo: Ática.

BANCO DO NORDESTE DO BRASIL S.A. 1996. Roteiro básico de apresentação de projetos de desenvolvimento institucional - DI. UEC - Unidade Executora Central. Fortaleza (Doc. Interno).

BENI, Mário C. 1990. Sistema de turismo - SISTUR: Estudo do turismo face à moderna teoria de sistemas. Turismo em Análise. São Paulo: ECA/USP, v.1, n.1.

EMBRATUR - Instituto Brasileiro de Turismo, 1994. Programa nacional de municipalização do turismo-PNMT. Brasilia: Embratur.

1996/dez. Relatório das atividades desenvolvidas pelo PNMT no período de novembro/95 a dezembro/96. 1996/dez., Brasília: EMBRATUR (Doc. Interno distribuído no Il Encontro Nacional do PNMT/Brasília/DF dez/96).

GOULDNER, Alvin W. 1959. Organizacional analysis. In: Robert K. MERTON et al (orgs.). Sociology today. New York: Basic Books, p. 405-4I0.

HALL, Richard H. 1972. The formal organizations. New York: Basic Books.

KASPAR, Claude. 1989. Recent development in tourism research and education at the university level. In: WITT, Stephen F.; MOUTINHO, Luis (ed.) Tourism marketing and management handbook. London: Prentice-Hall.

MONTANA, Patrick J. e CHARNOV, Bruce H. 1998. Administração. São Paulo: Saraiva. (Série Essencial).

MORSE, Chandler. 1961. The individual and pattern variables. In: BLACK, M. (org.) The social theories of talcott parsons. Englewood Cliffs, N.J.: Prentice-Hall.

PARSONS, Talcott. 1956. Suggestions for a sociological approach to the theory of organizations. Administrative Science Quaterly, I:63-85.

PARSONS, Talcott. 1951. The social system. Glencoe, III:Free Press.

SUDENE - Superintendência do Desenvolvimento do Nordeste. 1994. PRODETUR/NE: Proposta de um modelo de gestāo para o PRODETUR. Ministério da Integração Regional. Superintendência do Desenvolvimento do Nordeste. Diretoria de Programas Setoriais. Recife.

VIEIRA, Marcelo Milano Falcão. 1997. Poder, Objetivos e Instituiçōes como determinantes da definição de qualidade em organizações brasileiras e escocesas. ANPAD - Associação Nacional dos Programas de Pós-Graduação em Administração: Revista de Administraçāo Contemporânea, v.1, n.1, p. 7-34.

Recebido em 12/01/98.

Aprovado em 14/04/98. 